\title{
Research on Welding Heat Affected Zone of Pipeline Steel in High Heat Input Welding
}

\author{
Jian-Ming WANG ${ }^{1, a}$, Yan LIU ${ }^{2, b, ~}{ }^{*}$, Kai WANG ${ }^{2, ~ c}$, Yang LIU ${ }^{1, d}$ \\ ${ }^{1}$ School of Mechanical Engineering, Shenyang University, Shenyang 110044, China \\ ${ }^{2}$ The Liaoning Provincial Key Laboratory of Advanced Materials \& Preparation Technology, \\ Shenyang University, Shenyang, 110044, China \\ awjmlucky1979@163.com, bliuyanneu@163.com, 'cwkai1991@foxmail.com, \\ dshendacaijialy@126.com \\ ${ }^{*}$ Corresponding author
}

Keywords: Pipeline Steel, Heat Affected Zone, Strength and Toughness, High Heat Input Welding.

\begin{abstract}
In this paper, the HAZ of pipeline steel in high heat input welding is researched, including the microstructure and properties of HAZ, the embrittlement of HAZ and the existing problems and solutions of HAZ. The results show that the welding normalized zone is the best part of the HAZ. The main embrittlement mode of HAZ in the pipeline steel is the coarse grained embrittlement and the microstructure embrittlement. The theoretical research system of adding nano-oxide induced the intra-granular acicular ferrit nucleation in HAZ will be a new research direction of solving the appearing problems of pipeline steel in high heat input welding.
\end{abstract}

\section{Introduction}

When the steel plates use the high heat input welding, the strength and toughness of the welding heat affected zone (HAZ) decreases with the increase of the heat input welding. In such a situation, further enhancement of HAZ toughness and strength in structural steel plates has come to constitute important development subjects in order to insure the safety of steel structures. Therefore, a new technology to obtain a fine-structured and high-toughness HAZ should be developed for the purpose of realizing excellent toughness in HAZ for high heat input welding using metallurgical thermodynamics, physical chemistry of metallurgy and material processing methods synthetically.

Accordingly, the HAZ of pipeline steel in high heat input welding is researched in this paper, including the microstructure and properties of HAZ, the embrittlement of HAZ and the existing problems and solutions of HAZ. The study can provide a reliable theoretical basis and technical support for the development and application of high heat input welding pipeline steel, which has good strength and toughness.

\section{Microstructure and Properties of Welding Heat Affected Zone}

The welding heat affected zone has a certain width. Different position will experience the different welding thermal circulation process due to the different distance from the welding line. Now we can make the peak temperature and the microstructure characteristics as the division standard, the welding heat affected zone is divided into four parts, including the welding overheated zone, the welding normalized zone, the partial phase transformation zone and the recrystallized zone [1].

\section{The Welding Overheated Zone}

It is also known as the coarse grained zone (CGHAZ). This zone is located adjacent to the fusion zone. The temperature range is from $1100{ }^{\circ} \mathrm{C}$ to the solidus temperature, so the heat is serious. Some insoluble carbides and nitrides are soluble in the austenite grains, which can make the original austenitic grains grow rapidly. The $\varepsilon$-carbides distribute in the original austenitic grains mainly in 
the morphology of the widmannstatten structure and produce the thick overheated structure after cooling. This microstructure determines the apparent aeolotropism and the very poor low temperature impact toughness and the crack easy to be generated in the coarse grained zone. The welding overheated zone is the weak link of the welding joint and become the researched and improved focus of many scholars.

\section{The Welding Normalized Zone}

This zone locates outside of the welding overheated zone. The temperature range is from $\mathrm{Ac}_{3}$ to the temperature of austenitic grain growth. Because the heating degree is not high in the welding normalized zone, the microstructure can be completely austenitized and the grains can't grow up quickly. It is equivalent to the normalizing treatment of the microstructure. So we can obtain the fine ferrite and pearlite and the good strength and toughness in this zone. The welding normalized zone is the best part of the welding heat affected zone.

\section{The Partial Phase Transformation Zone}

The temperature range is from $\mathrm{Ac}_{3}$ to $\mathrm{Ac}_{1}$. During the cooling process, the pearlite is completely transformed into the austenite, only a small part of ferrite dissolves and distributes as the fine dispersed phase in the grown austenitic. Therefore, the mechanical properties are seriously uneven in the partial phase transformation zone. The strength and toughness are not better than that in the welding overheated zone.

\section{The Recrystallization zone}

It is also known as the tempering zone, which produces only when the parent material proceeds with the cold working before the welding. The temperature range is from $\mathrm{Ac}_{1}$ to $450^{\circ} \mathrm{C}$, which is basically the same as the high-temperature tempering temperature. The microstructure is similar to the elongated grains of the base material after rolling. The mechanical properties, which are similar to that of the base material, just have the very small change in this zone. So the recrystallization zone has little effect on the properties of the base material [2].

\section{Embrittlement of Welding Heat Affected Zone}

Strength (mainly yield strength and tensile strength) and toughness (mainly low temperature impact toughness) are the important standard for measuring the comprehensive properties of pipeline steel. The low temperature impact toughness of the coarse grain zone is very poor in welding heat affected zone, the reason is that the microstructure of the quasi-polygonal ferrite and polygonal ferrite mainly forms during the welding thermal process, which destroys the mainly existing anisotropy and mutual close-packing acicular ferrite microstructure in base material, causes the embrittlement of CGHAZ and reduces the mechanical properties of welded joints significantly. Accordingly, the development of pipeline steel is restricted greatly [3]. The main embrittlement mode of welding heat affected zone in the pipeline steel is the coarse grained embrittlement and the microstructure embrittlement.

\section{The Coarse Grained Embrittlement}

This is because the austenite grain in the coarse grained zone grows up seriously by the heat. As a result, the specific surface area of the grain boundary decreases, the interfacial energy reduces, the grain boundary structure becomes loose and the hindrance effect of dislocation glide weakens. All above lead to the decrease of the low temperature impact toughness and the serious microstructure embrittlement. Fig.1 shows that the ductile-brittle transition temperature increases with the increasing of the grain size [4]. 


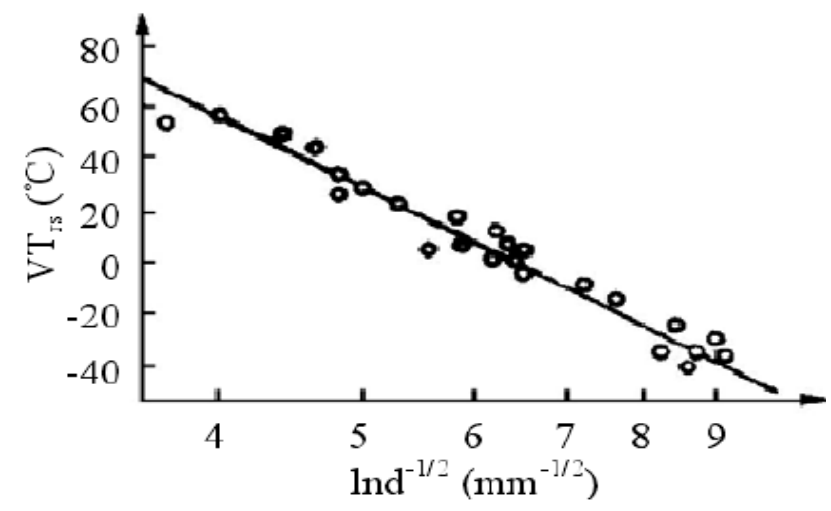

Fig.1 The effect of grain size on the temperature of ductile-brittle transition

\section{The Microstructure Embrittlement}

It is caused by the hard and brittle microstructures produced during the continuous cooling process of welding thermal cycle. Hard and brittle phases are always the upper bainite, high carbon martensite, residual austenite and M/A component. M/A component is the most common microstructure in pipeline steel. It has notable influence on the strength and toughness of pipeline steel. The embrittlement effect of M/A component is mainly analyzed as follows [5].

$\mathrm{M} / \mathrm{A}$ component is not a single phase microstructure. It is formed by the high-carbon twin martensite and retained austenite in the moderate cooling rate of welding thermal cycle. It is a kind of microstructure of large composition range. The single form of martensitic and austenitic is unable to distinguish, so we call it martensite-austenite microstructure. In the cooling process of welding thermal cycle, the undercooled austenite continues to transform into the ferrite of low solid solubility of carbon, which leads to the entrance of the residual carbon into the unchanged austenitic and the formation of carbon-enriched austenite. After rapid cooling, the high carbon martensite forms. The composite of the high-carbon martensite and retained austenite forms M/A component $[6,7]$.

The substructure of M/A component is primarily twins microstructure, which is formed by the dislocation climb and its symmetry is very high. When the content of $\mathrm{M} / \mathrm{A}$ increases, the strength of pipeline steel increases, but the toughness decreases, as shown in Fig. 2. In addition, the study found that the influence of M/A component on the mechanical properties of pipeline steel related not only to the quantity, but also to its distribution uniformity and existing forms. The fine and uniform-distribution M/A component is beneficial to improve the toughness of pipeline steel. But the M/A component of the larger size, uneven distribution and serious segregation will reduce the toughness of pipeline steel. The primary forms of M/A component in steel are mainly the strips and granules. Compared with the strips, the granules have less damage on the microstructure and properties [8,9]. The granular M/A component is easier to get in the lower-middle welding heat input conditions.

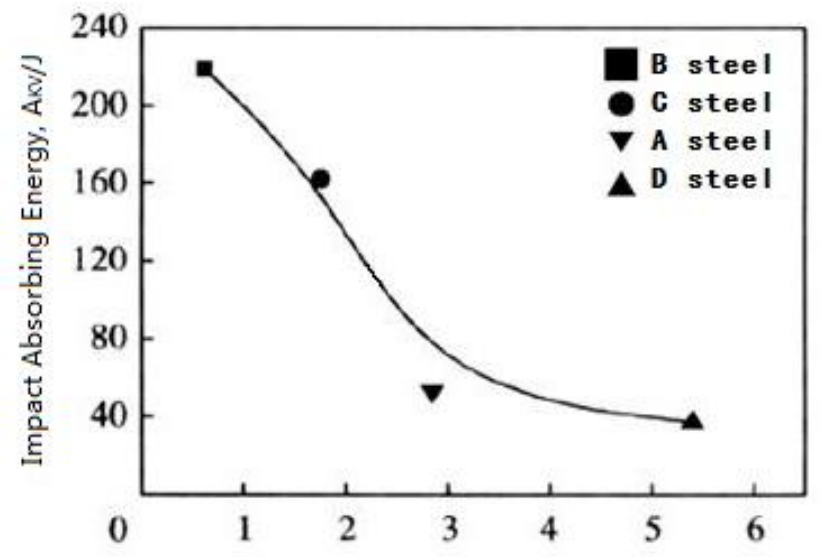

Fig.2 The relation of the area fraction of M/A and impact absorbing energy 


\section{The Existing Problems and Solutions of Heat Affected Zone of Pipeline Steel in High Heat Input Welding}

When the energy input is over $50 \mathrm{~kJ}$, we call it high heat input welding. It is true that high heat input welding has special significance for X80 pipeline steel. The Increase of the energy input can improve the welding efficiency of pipeline steel and save the cost of production. However, at the same time, the coarse grain causing by overheating and the softening and embrittlement in partial microstructure will seriously affect the mechanical properties of pipeline steel HAZ, in particular will lead to the decrease of impact toughness at low temperature [10]. So we need to find a method of optimizing the microstructure and mechanical properties of pipeline steel HAZ in high heat input welding conditions.

Scholars mainly explored the following aspects, such as the composite micro-alloying of $\mathrm{Nb}$ and $\mathrm{Ti}, \mathrm{Al}, \mathrm{Ti}, \mathrm{Mg}, \mathrm{Zr}$ alloy oxides and the complex oxide micro-alloying and $\mathrm{Ca}$ treatment desulfurization technology, and so on. However, the theoretical research system of adding nano-oxide induced the intra-granular acicular ferrit nucleation in HAZ of pipeline steel is blank and should be established. Therefore, it will be a new research direction of solving the appearing problems of X80 pipeline steel in high heat input welding.

\section{Conclusions}

The HAZ of pipeline steel in high heat input welding is researched in this paper, including the microstructure and properties of HAZ, the embrittlement of HAZ and the existing problems and solutions of HAZ.

(1) The HAZ has a certain width. Different position will experience the different welding thermal circulation process due to the different distance from the welding line. The welding normalized zone is the best part of the HAZ.

(2) The main embrittlement mode of HAZ in the pipeline steel is the coarse grained embrittlement and the microstructure embrittlement. M/A component is the most common microstructure in pipeline steel. It has notable influence on the strength and toughness of pipeline steel.

(3) The coarse grain causing by overheating and the softening and embrittlement in partial microstructure will seriously affect the mechanical properties of pipeline steel HAZ, in particular will lead to the decrease of impact toughness at low temperature. So the theoretical research system of adding nano-oxide induced the intra-granular acicular ferrit nucleation in HAZ of pipeline steel is blank and should be established. It will be a new research direction of solving the appearing problems of X80 pipeline steel in high heat input welding.

\section{Acknowledgments}

This work was supported by the Liaoning Province Natural Science Fund Project (No. 2014020097), the Project for Liaoning Provincial Scientific Research in University of China (No. L2014475) and the Open Subject Fund of the State Key Laboratory of Rolling and Automation of NEU, China (No. 2009003).

\section{References}

[1]H. Liu, H.L. Gao, X.G. Ding, Influence of welding thermal cycle on structure and properties in grain-coarsening region of X80 pipeline steels, Hot working Technology. 7 (2007) 4-6.

[2]R.H. Hao, H. Niu, H.L. Gao, Toughness distributions of different area on HAZ of grade X80 pipeline steel, Welded Pipe and Tube. 1 (2006) 23-25.

[3]W.Y. Zhang, Welding Metallurgy, M. China Machine Press, Beijing, 1993, pp. 195-204.

[4]X.L. Xu, X.X. Xin, K. Shi, Study on control factors of welded pipeline steel coarse grain area 
toughness, C. Annual meeting of the China Iron and Steel. (2001) 226-230.

[5]Y.Q. Zhang, H.Q. Zhang, W.M. Liu, Effects of M-A constituent on toughness of coarse grain heat-affected zone in HSLA steels for oil tanks, J. Transactions of the China Welding Institution. 1 (2009) 109-112.

[6]L. Zhao, W.Z. Chen, X.D. Zhang, Structure character of M-A constituent in CGHAZ of new ultra-low carbon banitic steel under laser welding conditions, J. Mater. Sic. Technology. 3 (2006) 382-387.

[7]E. Bonnevie, G. Ferriere, A. Ikhlef, Morphological aspects of martensite-austenite constituents in intercritical and coarse grain heat affected zones of structural steels, Materials Science and Engineering A. 385 (2004) 352-358.

[8]C.M. Wang, X.F. Wu, Transmission electron microscopy of martensite/ austenite islands in pipeline steel X70, Materials Science and Engineering. 440 (2006) 267-271.

[9]W.W. Li, Y.X. Liu, H.L. Gao, Analysis of toughness in HAZ for X80 pipeline steel welding, Welded Pipe and Tube. 2 (2006) 43-46.

[10]H.L. Li, Several Hot Issues about research and application of steel pipe for natural gas transportation, China Mechanical Engineering. 3 (2001) 349-352. 